\title{
Building Alliance Capability:
}

\section{Management Techniques for Superior Alliance Performance}

\author{
Johan Draulans, Ard-Pieter deMan and Henk W. Volberda
}

Despite the fact that they represent a growing element of business strategy, alliances between organisations quite often result in failure. This is partly due to the fact that firms have not built up adequate capabilities to manage alliances. Special management techniques have to be implemented in order to strengthen the organisation's alliance capability. This article evaluates a number of these techniques with regard to their impact on alliance success, and reports on a quantitative study on alliances and alliance-management techniques of 46 large companies to assess this impact.

(c) 2003 Published by Elsevier Science Ltd

\section{Introduction}

Co-operation between firms is not a new phenomenon - businesses have entered into alliances for centuries. There is, however, a clearly discernible increase in the use made of alliances: during the past two decades the number of alliances between companies has increased substantially. At the same time, the success rate remains low, and many alliances are terminated without achieving the desired result. According to the managers concerned at least half the alliances entered into may be described as a failure within four years, while research by KPMG Alliances has even indicated a failure rate of as high as $60-70 \% .^{1}$

The fact that so many alliances fail despite the marked need for them makes them an interesting subject for research. Accordingly, numerous surveys have been conducted into the success and failure factors, but the success rates of alliances have not improved. Apparently all this research is not generating the required answers. Research has, however, concentrated in particular on alliance characteristics and structure such as the nature of the contracts, the type of alliance and whether or not there is co-operation with competitors, etc. In addition the emphasis is placed on the organisational, strategic, cultural and personal fit between alliance partners: an optimal fit is believed to raise alliance success. Little attention has been devoted to alliance management. Nevertheless there are businesses with a proven track record in the alliance field. Examples include Hewlett Packard (see Box 1), Nike and Cisco. It may be that the most important success factor is not the characteristics of the alliance but the skills of the alliance partners in managing alliances. 
This skill is referred to in the literature on alliances as alliance capability or alliance skill. ${ }^{2}$ It is defined as the ability to create successful alliances, based on learning about alliance management and leveraging alliance knowledge inside the company. As a result of the experience built up in this field, the idea arose within the KPMG alliance consultancy group that other factors besides alliance characteristics needed to be studied in order to explain the success and failure of alliances. It was based on their practical experience that certain organisations performed better than others in the field of alliances, while less successful organisations appeared to be incapable of making their alliances work. Instead of answering the question of why certain alliances are more successful than others, it is better to examine why certain organisations are more successful with alliances than other organisations. Factors such as the knowledge, experience and management techniques that the organisations have in the alliance field could be examined, making the organisation instead of the alliance the frame of reference for research.

\section{... the organisation instead of the alliance (becomes) the frame of}

\section{reference}

The Alliance Success of Hewlett Packard. ${ }^{3}$

Twelve years ago Hewlett Packard entered into an alliance with Canon in the field of laser printers. The PC know-how of HP was combined with Canon's knowledge of the laser engine, the most expensive part of a laser printer. HP used the Canon engines in the production of its laser printers, thereby managing to increase its share of this 6 billion guilder market within a few years from virtually $0 \%$ to $70 \%$. Building on the success with Canon, HP also makes use of products developed in partnership with suppliers for other products.

As a result of these highly successful alliances, the feeling arose within HP that the knowledge acquired in the past could be used for future alliances. Responsible managers indicated to the board that now that they had the necessary experience, the alliance knowhow should be geared more closely to Hewlett Packard's specific situation. HP responded by developing activities which could institutionalise the alliance knowledge and skills in a well-structured approach. Best practices from the organisation itself were communicated among the responsible managers through regular training courses. Checklists were drawn up for managers as an aid towards the successful conclusion of their alliances. In addition various alliances are regularly evaluated individually and compared with one another at top level. In this way HP became a learning organisation in the alliance field.

An interesting feature of this approach towards alliances is that it fits in with competence-based strategy theory, which is concerned with the building up of competencies and the learning capacity of organisations ${ }^{4}$ Like any other competence the management of alliances is a skill that can be built up and which can become a significant source of competitive advantage.

This article will firstly go into the theory of alliance capability. Because of the novelty of this viewpoint, little research has been done. ${ }^{5}$ After this theoretical exposition, report will be made of a statistical research project, which was performed in 46 companies (including 40 Fortune 500 companies and 6 large Dutch non-Fortune 500 companies). The main aim of this research was to get a first quantitative underpinning of our ideas about alliance capability development. Some management techniques related to incorporating knowledge about alliance management into the organisation are evaluated, as well as whether and how these techniques are being used and whether they lead to more successful alliance management.

The research shows that paying attention to alliance management by investing in alliance training, alliance specialists and alliance evaluation raises alliance success rates. These mechanisms 
enable companies to really profit from their alliance experience. More specifically, inexperienced organizations benefit from evaluating individual alliances and sending staff to alliance training. Organizations with a larger number of alliances should evaluate alliances by comparing them to each other. As far as alliance specialists are concerned, companies locating them close to practice outperform companies which locate them near top management.

Differences between companies in terms of structure, culture and

planning need to be bridged.

\section{Towards an alliance capability theory: a knowledge-based perspective}

Alliances involve two or more partners sharing knowledge (or other resources) and coordinating their activities. Coordination of activities between two independent organizations differs in a number of respects from the coordination of activities inside organizations. Differences between companies in terms of structure, culture and planning need to be bridged. This requires specific skills and knowledge absorption of the partner firms involved in the alliance.

The building up of firm level capabilities based on absorbing knowledge from inside and outside the firm has received considerable attention from a variety of authors, specifically with regard to technological capabilities. ${ }^{6}$ But organisational capabilities of a non-technological nature can be built up as well. ${ }^{7}$ In their Evolutionary Theory of Economic Change, Nelson and Winter present firms as repositories of routines which endow them with a capacity to search. In a similar way, the firm in the resource-based theory is seen as a bundle of tangible and intangible resources and tacit know-how that must be identified, selected, developed, and deployed to generate superior performance (Barney; Conner and Prahalad; Wernerfelt,). In this connection, Teece, Shuen and Pisano suggested that the relative superiority of firm-specific resources and routines cannot be taken for granted and that, from a normative perspective, the firm must always remain in a dynamic capability building mode, retaining its capacity to renew, augment, and adapt its routines and competencies over time. In the strategy field we therefore see increasing attention to the dynamic capability approach ${ }^{8}$ in which the emphasis is on developing capabilities by absorbing knowledge inside and outside the organisation.

In this connection, Grant states that the essence of these dynamic capabilities is the integration of individuals' specialised knowledge and that the primary role of the firm is the integration of this knowledge. ${ }^{9}$ Moreover, Lane and Lubatkin showed that the ability of a firm to learn from another firm is jointly determined by the relative characteristics of the two firms, hence their emphasis on relative absorptive capacity, and that on the basis of their empirical findings, a firm's knowledge processing system plays a key-role in absorbing knowledge. ${ }^{10}$ Finally, Van den Bosch, Volberda and De Boer argue that the level of absorptive capacity not only depends on the firm's organisational form but also on its capabilities to combine knowledge. ${ }^{11}$

In this article, one specific type of capability is studied, namely the capability to manage alliances successfully. Although every alliance is unique, the processes of alliance management share certain features. The capacity to manage alliances and absorb knowledge on alliances is a distinct management capability: the alliance capability. According to Kale, Dyer and Singh an alliance capability is defined as the mechanisms and routines that are purposefully designed to accumulate, store, integrate, and diffuse relevant organisational knowledge about alliance management. ${ }^{12}$ In this article, three of those mechanisms are studied: alliance training (to accumulate and diffuse knowledge about alliances), the presence of an alliance specialist (storing, integrating and diffusing alliance knowledge) and alliance evaluation mechanisms (aimed to accumulate knowledge based on a firm's own alliance experience with its partners). The basic idea underlying the argument is that companies possessing an alliance capability will exhibit higher alliance success rates than those that have 
not invested in building up an alliance capability. In this way they are able to create a source of competitive advantage at firm level.

Literature on alliances does not provide many clues about the precise nature of alliance capability, and the build-up and effective use of knowledge about alliance management is not a topic that has received much attention. Research has touched upon the subject only indirectly, by focusing on firms' experiences with alliances. Specifically, research into the proclivity of companies to enter into alliances has found that positive experiences with alliances lead companies to partner again. Apparently, some companies have a better alliance performance than others. However, an explanation as to why some companies have positive experiences while others have not is lacking. There are quite some insights into the success of individual alliances, but an explanation for alliance success at the company level is absent. Also, most authors assume a 'learning-by-doing' model, stating that the number of alliances a company has entered into ${ }^{13}$ or the number of years a company has been involved in alliances ${ }^{14}$ indicate the level of alliance experience. The mechanisms used to transfer this experience into practical knowledge for alliance managers are not discussed. One of the most interesting findings is by Anand and Khanna who find that companies learn to manage inter-firm alliances as experience accumulates. ${ }^{15}$ They believe this reflects the existence of an alliance capability. They also conclude that the way in which this learning takes place

How do companies learn about alliance management?

remains unclear and consequently they point out the need for 'data internal to each firm regarding the organisation of their alliance management processes, possibly collected through surveys'. This article aims to do just that: find out what management tools and processes companies use to learn about alliance management, to distil management lessons from their experience and to diffuse those lessons inside the organisation. Previous research has answered the question whether companies learn about alliance management and the conclusion is that they do. It has not studied how companies learn about alliance management.

Others have found that some companies have more alliances than others. Especially reputed companies appear to attract more partners. ${ }^{16}$ These studies do not delve into the question whether more partners also translate into higher alliance success rates and if so, why. Hakansson looks into the effect of prior contact between companies and finds that companies that have cooperated previously are more successful when they enter into an alliance again with the same partner. ${ }^{17}$ Hence, on a company level, companies may build up a capability to work with a specific partner. Hakansson does not discuss a key aspect of alliance capability, viz. whether the capability of working with a specific partner is transferable to alliances with other partners. This brief overview of academic research confirms the observation that academic research has 'neglected concepts/measures that focus on alliance management' (Spekman et al. ${ }^{18}$ ) as an explanatory variable for alliance success.

In management literature on the other hand, much has been written about alliance management tools and processes. ${ }^{19}$ However, these studies are qualitative and have not empirically linked alliance management processes to alliance success. So far only Kale, Dyer and Sing have performed research related to this question. They find that building a dedicated alliance management function leads to higher alliance success rates. They ascribe this finding among others to improved knowledge management: a dedicated alliance function helps to improve learning and leveraging lessons from alliances. ${ }^{20}$ This article extends this finding by not only looking at a dedicated alliance function (the alliance specialist), but also at specific methods to gather alliance knowledge, viz. alliance training and evaluation methods.

\section{Research design}

In order to study whether an alliance capability is important and how an organisation can develop such a capability, KPMG Alliances and the Erasmus University Rotterdam/Rotterdam School of 
Management jointly conducted a survey to which 46 large companies responded. Members of the managing boards of the organisations were approached by means of a questionnaire and personal interviews. The respondents were asked questions about the alliances of their organisations, the success of those alliances, knowledge of and experience with these alliances and the way in which the organisation evaluates its alliances (see Appendix 1).

The degree of success is measured in the current situation on the basis of alliances which the organisation had set up three to six years ago. The questions concerning the management techniques used for alliances related to the same period. It was then investigated whether there was any correlation between management techniques used and the success of the alliance (see Appendix 1).

The success of alliances was determined on the basis of three success indicators, where the respondents were able to indicate on the basis of a seven-point scale whether they considered that the performance of the alliances had exceeded or fallen short of expectations. Success issues were measured on a 7-point Likert scale. The presence of alliance management mechanisms was measured by means of multiple-choice questions. Alliance success was determined according to the following criteria:

1 economic/financial performance;

2 the extent to which the goals had been achieved;

3 the relationship between the partners;

4 overall performance.

\section{Research findings}

The results of the research are presented below. They are significant at a 5\% level. The results concern four topics all of which are related to the formation or existence of an alliance capability:

- the number of alliances;

- the use of evaluation methods;

- the use of an alliance specialist;

- the use of alliance training.

\section{The number of alliances}

The research indicates that the success of an organisation's alliances rises as it enters into more alliances. The relationship is however curvilinear: although an increase in the number of alliances is systematically associated with greater success, the increase becomes less marked as the number rises (see Figure 1).

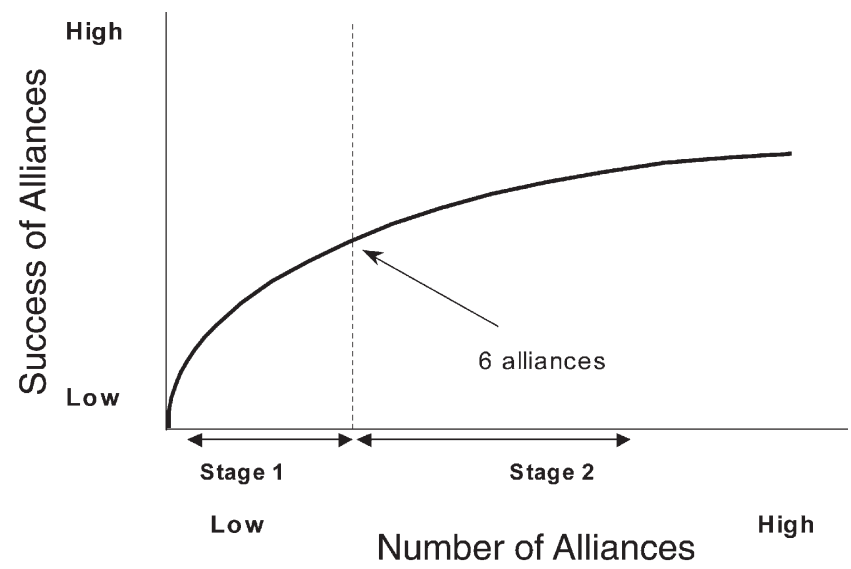

Figure 1. Relationship between the number of alliances and the success of the organisation's alliances. (Regression analysis showed a Rsquare of 0.17 with a significance level of $2 \%$ ) 
The initial conclusion to be drawn from these facts is that these organisations evidently gain practical experience with alliances. This is the first indication of the existence of an alliance capability.

\section{there is a limit to learning-by-doing}

The second conclusion is that there is a limit to learning-by-doing. Our dataset suggests a turning point at around six alliances. This is an estimate based on the point where the curvilinear line starts to flatten, indicating that learning-by-doing has reached its limits. After that level of experience little improvement in alliance success is gained from entering into further alliances.

Apart from general experience, our research also examined whether organisations having specialised experience (such as experiences in alliances with a particular goal, e.g. market access or product development), were more successful than organisations lacking such specialised knowledge and experience. Particularly in the case of knowledge-intensive alliances, like those aimed at the 'development of new products and/or technology' and 'acquisition of knowledge', earlier experience turns out to play a major role in the success of alliances. A possible explanation for this result is that due to the complexity of this type of alliance, learning from previous experience is of even greater importance than in simple alliances.

As became clear in Figure 1, experience does not increase alliance success indefinitely. It may be that companies are able to handle only a limited amount of alliances simultaneously. With more than six alliances a company may surpass its capacity to manage those alliances at the same time. At a later point, it may have increased its experience and, consequently, its success rate. It would require longitudinal research to explore this. A more likely explanation is that there is a limit to learning-by-doing. If the success of alliances cannot be further improved from a certain level of experience by gaining still further experience, how then can success be improved? A possible answer to this question is that the learning needs to be more structured. By institutionalising and structuring learning from experience it may become possible to increase the success rate of alliances. This has been investigated in our dataset. Three ways of structuring alliance knowledge and experience were examined: evaluation, the use of alliance specialists, and the use of alliance training.

\section{Use of evaluation methods}

The extent to which the use of evaluation methods affects the success of an organisation's alliances was also examined. Two evaluation methods were considered. The first is the unstructured evaluation at individual alliance level. The second is cross-alliance comparison of the various alliances of the organisation.

... the evaluation of individual alliances have an effect for inexperienced companies, but not... for experienced companies

\section{Evaluation per alliance}

The individual evaluation of alliances did not initially reveal any significant effect on success. Nor did this prove much more effective than no evaluation whatever. However, on the basis of the number of alliances represented in Figure 1 organisations may be subdivided into an experienced (over six alliances) and an inexperienced (fewer than six alliances) group. We hypothesized that the evaluation of individual alliances does have an effect for inexperienced companies, but not so much for experienced companies. Inexperienced companies will still learn much from a simple form of evaluation. Experienced companies on the contrary will learn few new lessons from a 
Table 1. Correlation of individual evaluation criteria used and alliance success

\begin{tabular}{lll}
\hline Independent variable & \multicolumn{2}{c}{ Dependent variable 'organisations alliance success' } \\
\cline { 2 - 3 } & $\begin{array}{l}\text { Correlation coefficient experienced } \\
\text { group }(1 \text { tailed sig. })\end{array}$ & $\begin{array}{l}\text { Correlation coefficient inexperienced } \\
\text { group }(1 \text { tailed sig. })\end{array}$ \\
\hline $\begin{array}{l}\text { Number of individual } \\
\text { evaluation criteria used }\end{array}$ & $0.017(0.468)$ & $0.359(0.05)$ \\
\hline
\end{tabular}

Table 2. Extent to which cross-alliance evaluation enhances success

\begin{tabular}{lc}
\hline Method for cross-alliance evaluation & Improvement/deterioration of average success \\
\hline No method & $-8 \%$ \\
Random method & 0 \\
Frequent formal method & $+30 \%$ \\
\hline
\end{tabular}

simple evaluation. Our study revealed that evaluation of individual alliances did indeed contribute to success in the inexperienced group but not in the experienced group. Table 1 shows the impact of evaluating individual alliances on the performance of the experienced and inexperienced groups. We also studied the scope of the evaluation, by looking at the number of evaluation criteria (financial success, good relationship etc.) the companies employed. The table shows that regardless of the number of evaluation criteria used, individual evaluation does not raise the success rate of the experienced group. The inexperienced group on the contrary, shows a remarkable increase in alliance success when evaluating individual alliances on a number of criteria. Given the fact that the variance in the number of evaluation criteria is similar for the two groups (with 0.79 for the experienced group a little higher than the 0.71 for the inexperienced group), we can conclude that individual evaluation does not raise the alliance success for experienced companies. Even when experienced companies evaluate their alliances on a number of criteria, they apparently do not derive any new insights that allow them to further increase alliance success. Evaluation does raise success rates for inexperienced companies and the broader the scope of the evaluation, the more so.

\section{Cross-alliance evaluation}

The second evaluation method that was investigated concerned the structured comparison of various alliances of the organisation with one another. A company can learn from comparing its alliance with company $\mathrm{X}$ with its alliance with company $\mathrm{Y}$. We will call this cross-alliance evaluation. This turned out to substantially increase the alliance success of the organisation (see Table 2). The most important learning effect is therefore gained by comparing various alliances frequently and in accordance with a set method. In practice this generally has the advantage that more people are involved in the evaluation, so that alliance knowledge is more widely distributed within the organisation at the same time. Also, as the number of alliances becomes large, the firm will have new opportunities for finding synergies among the various partners. These synergies will only be found by comparing alliances with each other. This network effect may explain our findings.

As with the analysis of individually evaluating alliances we also compared the effect of using frequent formal cross-alliance evaluation methods for experienced versus inexperienced organisations. It showed that the experienced group benefits especially from this type of evaluation (see Table 3). 
Table 3. Extent to which the use of frequent formal cross-alliance evaluation enhances success for experienced vs. inexperienced organisations

\begin{tabular}{llc}
\hline Use of cross-alliance evaluation & \multicolumn{2}{l}{ Improvement/ deterioration of average success } \\
\cline { 2 - 3 } & Experienced group & Inexperienced group \\
\hline $\begin{array}{l}\text { Frequent formal cross-alliance evaluation } \\
\text { method used }\end{array}$ & $+17 \%$ & $+2 \%$ \\
\begin{tabular}{l} 
No cross-alliance evaluation methods used \\
\hline
\end{tabular} & $-7 \%$ & $-14 \%$ \\
\hline
\end{tabular}

\section{The experienced group benefits particularly from comparing various}

\section{alliances with one another.}

\section{Conclusion with respect to evaluations}

The conclusion is that the inexperienced group should in particular make use of methods for evaluating individual alliances. The experienced group by contrast benefits particularly from a more advanced method, which compares the various alliances with one another.

This result may be explained by the low level of knowledge in the inexperienced group. The fact that inexperienced firms know little about alliances means that even a rudimentary form of evaluation contributes to the formation of alliance know-how. The complex method of evaluating may be too cumbersome for these kinds of firms. For firms with a limited number of alliances there is no merit in introducing complex methods of alliance management. If the number of alliances increases, however, more complex methods turn out to be both required and useful for moving to the next alliance capability level.

\section{Organisations with a specialist are considerably more successful with}

alliances than those lacking one.

\section{Use of an alliance specialist}

Besides looking at evaluation methods, our research examined whether concentrating alliance knowledge and experience in certain individuals increases the success of the organisation's alliances. Such alliance specialists are persons involved in and responsible for multiple alliances. Organisations with a specialist are considerably more successful with alliances than those lacking one. The level at which the specialist was positioned in the organisation also proved to be of decisive importance. The results show that the lower the individual is placed in the organisation - closer to the action - the greater the success (see Table 4).

The figures in Table 4 do not imply that senior management should not devote any attention

Table 4. Extent to which the use and level of an alliance specialist enhances the success of alliances

\begin{tabular}{lc}
\hline Level of alliance specialist within firm & Improvement/deterioration of average success \\
\hline Top management/senior level & $0 \%$ \\
Middle management/low level & $+25 \%$ \\
No specialist & $-20 \%$ \\
\hline
\end{tabular}


to alliances. They show that the person who is responsible for and involved in multiple alliances should be placed at a lower organisational level. When the specialist forms part of senior management, he or she probably is too far from the practical scene to make a genuine impact on the success of the alliance.

Further research into the experienced and inexperienced group indicated in particular that the success due to having an alliance specialist rises among experienced organisations. A possible explanation is that the specialist is able to accumulate the knowledge and experience of a large number of alliances and to make these accessible to the organisation. In this way he or she will enhance the alliance capability of the organisation. Organisations with a low number of alliances will have little to gain from an internal specialist since there is little organisation-specific knowhow and experience to be institutionalised.

\section{Use of alliance training}

A third activity which can be undertaken in order to promote the success of the organisation's alliances is the organisation of training courses. According to a number of authors, 'tacit knowledge', such as alliance knowledge and experience, can be transmitted to managers by such means as training. ${ }^{21}$ Training can either be internal (by company specialists) or external (e.g. by consultants or academics). Both types of training are incorporated in our variable 'alliance training'. Analysis of the data indicates that the use of alliance training increases the success of the organisation's alliances. Organisations using training have an alliance success rate $10 \%$ above the average for the whole sample group, while those not using training score $15 \%$ below average (correlation coefficient of 0.223 with a significance level of $4.6 \%$ ).

Here again experienced and inexperienced organisations were looked at. Training turns out to be most effective for organisations lacking alliance experience. Experienced organisations benefit less from training (see Table 5).

An interesting question is the extent to which this result can be explained by the nature of alliance training. Most of the training courses known to the authors concentrate on alliance characteristics and the fit between the partners. This is logical since most of the research has been concerned with these aspects. This kind of training is of interest to organisations with a low level of alliance-knowledge. For experienced organisations, however, they may not add much further value and insight.

\section{Levels of alliance capability}

The research reveals that the availability of an alliance capability increases an organisation's alliance success. The more alliances an organisation enters into the greater the success of those alliances. The relationship is however curvilinear: although the number of alliances is correlated with the level of success, the increase declines as the number rises. There appears to be a turning point at around six alliances, on the basis of which the organisations investigated may be divided into two groups, alliance-inexperienced or alliance-experienced. The stage at which the organisation finds itself determines the effectiveness of the management method to be employed (evaluations, alliance specialist, training).

Beyond a level of six alliances, a further level of development of alliance capability is required

Table 5. Extent to which the use of alliance training enhances the success of alliances

\begin{tabular}{lll}
\hline Use of alliance training & \multicolumn{2}{l}{ Improvement/deterioration of average success } \\
\cline { 2 - 3 } & Experienced group & Inexperienced group \\
\hline Alliance training used & $+1 \%$ & $+65 \%$ \\
No alliance training used & $-2 \%$ & $-11 \%$ \\
\hline
\end{tabular}


in order to increase the success of the organisation's alliances. The management techniques used in the inexperienced group will then cease to be adequate for increasing the success any further.

The dotted upper lines in Figure 2 indicate what happens in our data with those companies in the experienced group, which make use of more advanced management techniques, like crossalliance evaluation and alliance specialists. They are capable of further increasing their alliance success (the line takes an upward path in stage 2, but there were not sufficient data to determine whether this is a linear or an exponential increase or how rapidly the line rises). Hence, our research shows different management techniques should be used in different stages of development of an organisation's alliance capability.

\section{Lessons for managers}

The first implication for management is fairly straightforward: it pays to actively pursue the building up and dissemination of alliance knowledge by attending or instituting alliance training (especially for inexperienced companies), appointing alliance specialists at middle management level and evaluating alliances, not only individually, but also against each other. In order to be successful with alliances, companies need to develop new processes in the internal organisation. These processes should be directed at learning from alliances, gathering knowledge about alliances from outside the company and spreading knowledge to alliance managers inside the company.

Secondly, an alliance capability does not have to be built up from scratch inside the company. Alliance training can help to avoid the more general pitfalls of partnering. Most training programs cover the various steps in the alliance process, types of alliances, joint business planning, the role of trust and managing cultural differences. Recently, specialized forms of training have come into being which aim at specific types of alliances (for example Internet alliances) or new alliance management processes (for example defining alliance metrics). The impact of these specialized types of training has not been incorporated in our data. It is possible that these advanced training programmes also increase the alliance success rate of experienced organisations. Companies on the brink of entering into an alliance for the first time should therefore consider sending their people to alliance training. Alliance specialists can be hired from outside to inject a company with

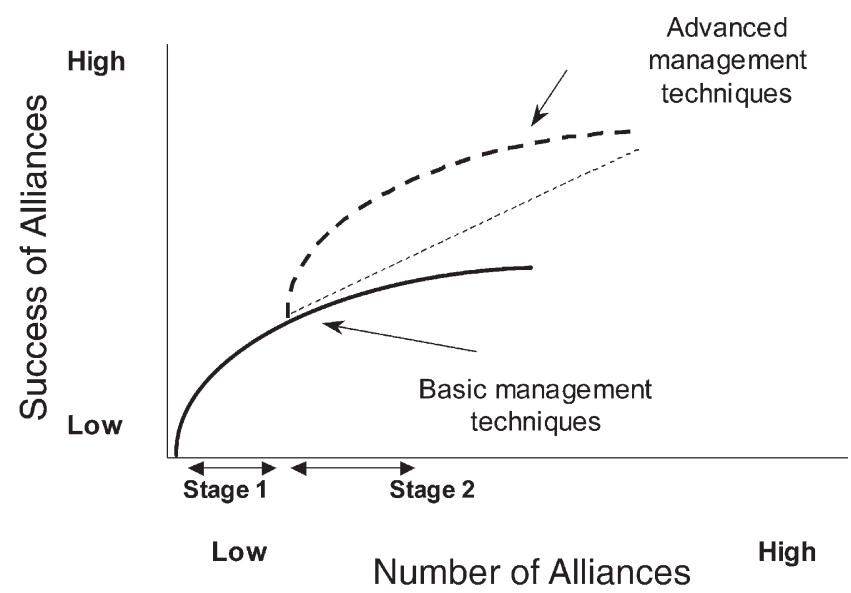

Figure 2. Stages in the development of an alliance capability (upper curve exists, but its shape is indicative) 
knowledge, to structure the alliance learning process and to transfer best practices inside the company. A limit to this route of building up an alliance capability is that a company needs the absorptive capacity to understand the alliance knowledge brought into the company. Companies with an 'alliance mindset' will find it easier to absorb and exploit alliance management knowledge from outside than companies without any prior knowledge about alliances. ${ }^{22}$ An alliance capability can therefore be bought in only up to a point: practical experience remains important.

A third issue is whether an alliance capability is built up fastest by entering into a diversity of alliances or by implementing similar alliances. Our research results seem to suggest that it is more sensible to do the latter. Alliance learning related to joint ventures (a separate company with the partners as shareholders) differs from learning related to licensing agreements, ${ }^{23}$ and different types of alliances (supply chain alliances, bilateral alliances and multi-partner alliances) have different requirements in terms of partner selection, management and upgrading of the alliance. ${ }^{24}$ Different types of alliances therefore require different types of alliance knowledge. Consequently, learning takes place faster when similar types of alliances are entered into than when different alliances are set up. In combination with the point made about alliance training above, an ideal learning trajectory would be to gather general alliance information by means of attending alliance training sessions and subsequently enter into a number of similar alliances and learn from them by means of evaluating them both individually and with each other. An alliance specialist may be brought in, but his or her experience should fit with the particular alliance type the company has opted to experiment with.

\section{An excellent match between partners (may not lead) to a successful}

\section{alliance}

Finally, when partners are selected for a new alliance, managers should not only look at the fit between their company and the prospective partner's company. The match between the companies in terms of strategy, structure and culture is only one important aspect. The alliance capability of the partner should be assessed as well. An excellent match between partners does not have to translate into a successful alliance. Our data suggest that when one of the partners is inexperienced in alliance management the chances of success will diminish.

\section{Conclusion and further research}

Traditional research into the success and failure factors of alliances appears to overlook an important element. The capability which an organisation has built up in managing alliances makes an important contribution towards enhancing alliance success. Existing research and consulting strategies concentrate unduly on the fit between the partners and the characteristics of the alliance instead of focusing on the capability of the partners to manage the alliance.

Various levels of alliance capability may also be distinguished. Each of these levels may call for different management techniques. A strategy to develop alliance capability should therefore be geared to the needs and development stage of the company in question:

- experienced organisations learn the most from the comparison of alliances with each other, while inexperienced organisations learn more from the individual evaluation of alliances. Of course this may be an evolutionary pattern: when inexperienced organizations enter into more and more alliances they will have to gradually change their alliance evaluation method;

- experienced organisations in particular benefit from the use of an alliance specialist, as long as the latter is able to exert influence on the operational practicalities of the alliance. A specialist needs to be close to practice;

- alliance training courses are particularly successful for inexperienced organisations. 
Of course, further work on alliance success in theory and in practice needs to be done. In our empirical study, alliance capabilities turned out to play an important role as an explanatory factor for alliance success and we showed that management and learning do matter in alliance success. We even identified several tools which should be developed for increasing alliance success. More in-depth case studies of how firms identify, assimilate and apply knowledge on alliances need to be done.

\section{Appendix 1: Research design and methods}

The research process consisted of three main phases.

1 Development of the questionnaire. After a review of relevant literature, four interviews of 60-90 minutes were conducted with Dutch multinational corporations, regarding their alliance strategy and alliance management. Together with the literature review, the interviews provided input to develop a questionnaire. The questionnaire was tested with the same four companies that participated in the interview sessions. The test phase provided valuable insights enabling us to improve the questionnaire. The final questionnaire consisted of some open ended questions, multiple choice questions to measure the alliance management tools in place and 7-point Likert scale questions to rate alliance success. A survey instruction accompanied the questionnaire, which included definitions of the type of alliances to be considered. Also respondents were asked to base their answers on alliances started 2-5 years prior to their filling out the questionnaire, in order to get a good measure of alliance success. The survey is available from the authors on request; a summary is added at the end of this Appendix.

2 Gathering data. The questionnaire was sent to the boards of 625 organisations (the 500 largest companies of the world and the 125 largest companies in the Netherlands (including some on the Fortune 500 list). 46 questionnaires were returned by 32 foreign companies (a $6 \%$ response rate) and 14 Dutch companies (an 11\% response rate, including 8 Fortune 500 companies). The response is in line with research to response rates of similar international mail-surveys in which expected rates of 6-12\% are reported..$^{25}$ Respondents were senior managers (CEOs, board members responsible for alliances, directors of Strategy/Business Development, top-level alliance managers). The companies varied in size (based on market cap) between Euro 105 million and Euro 65 billion. The average number of alliances each organisation started between 1993 and 1996 was 14. Participating companies operate in a broad field of sectors (insurance, banks, motor vehicles, utilities, airlines, chemicals, telecom \& IT, food and merchandising, petroleum, aerospace) and a variety of countries (Brazil, Germany, Great Britain, Japan, Spain, Switzerland, the Netherlands and United States). We found no significant differences between alliance behaviour of Dutch and foreign firms. For example analysis showed both groups have the same alliance success-rate and both are engaged in approximately the same number of alliances (13 for Dutch firms vs. 14 for foreign firms). Alliance success was rated according to four successindicators (economic/financial, goals attained, harmony among partners, overall performance), measures that had been found in the alliance literature. ${ }^{26}$ The respondent was asked to rate the success of the alliances of his organisation for each of these indicators on a 7-point Likert scale. The average of the four success indicators was calculated and used in our statistical study as being the dependent variable 'organisation's alliance success rate'. The four success measures were highly correlated.

3 Statistical analysis. For our statistical analyses we made use of SPSS. Relationships were tested with the functions 'Correlations' (Pearson Correlation), 'T-test' (test for equality of means) and 'One Way Anova' (analysis of variance). We used least square analysis. Next to the research reported in this article, we also examined whether experience with similar types of alliances leads to improvement in an organisations alliance success rate. Experience with similar types was measured according to three variables: experience with alliances started for the same objec- 
Table 6. Components and scale items used in research

\begin{tabular}{|c|c|c|}
\hline Construct & Scale Items & Coefficient Alpha \\
\hline Number of alliances & Number of alliances started between 1993 and 1996 & $\begin{array}{l}\text { (not applicable; single } \\
\text { item analysis) }\end{array}$ \\
\hline Performance & $\begin{array}{l}\text { Economic performance of the alliances of the organisation } \\
\text { Establishment of goals } \\
\text { Harmony among partners } \\
\text { Overall performance }\end{array}$ & 0.92 \\
\hline Alliance topic & Information gathered with respect to topic & \\
\hline Alliance experience & $\begin{array}{l}\text { Number of alliances the organisation started between } 1993 \text { and } \\
1996 \\
\text { Objective of the alliances } \\
\text { Alliance with competitors } \\
\text { Countries from which partners originate }\end{array}$ & (not applicable) \\
\hline $\begin{array}{l}\text { Evaluation of } \\
\text { alliances }\end{array}$ & $\begin{array}{l}\text { Individual criteria used to evaluate performance of an alliance } \\
\text { How the performance of organisation's alliances was compared } \\
\text { which each other }\end{array}$ & (not applicable) \\
\hline Alliance specialist & $\begin{array}{l}\text { Departments responsible for alliances and their responsibilities } \\
\text { Level in organisation were specialist is located } \\
\text { Selection criteria for specialist }\end{array}$ & (not applicable) \\
\hline Alliance training & $\begin{array}{l}\text { By whom training is given } \\
\text { Regularity of training }\end{array}$ & (not applicable) \\
\hline
\end{tabular}

tive, alliances started with partners originating from the same country and alliances started with competitors. We found no significant relationship between experience with similar types of alliances and an improvement of the success rate. In our research we used one construct in which a number of scale items were used. Most other calculations relate to single item analysis. However, this does not mean we only used one question to explain a certain research topic. Table 6 shows the topics concerning alliances touched by means of survey questions. For the construct with multiple scale items a coefficient alpha is shown.

Correlation coefficients for the four independent variables (number of alliances the organisation has started in the past, use of evaluation procedures, use of alliance specialist, use of alliance training) are shown below in Table 7. The relationship between the number of alliances and the organisations alliance success rate is graphically presented in Figure 1. This relationship is curvilinear. Regression analysis showed an Rsquare of 0.17 with a significance level of $2 \%$.

The differences between the alliance-experienced organisations and the less experienced proved

Table 7. Correlation coefficients and significance level

\begin{tabular}{lll}
\hline Independent variable & \multicolumn{2}{c}{ Dependent variable 'organisations alliance success' } \\
\cline { 2 - 3 } & Correlation coefficient & Significance level \\
\hline 1. number of alliances & 0.323 & 0.029 (2 tailed sign.) \\
2. evaluation criteria used & 0.257 & 0.044 (1 tailed sign.) \\
3. use of an alliance specialist & 0.382 & 0.004 (1 tailed sign.) \\
4. use of alliance training & 0.223 & 0.046 (1 tailed sign.) \\
\hline
\end{tabular}


to be a statistically significant distinction. The less experienced group consists of 19 cases, the experienced of 27 cases.

\section{Appendix II: Abbreviated survey}

A. Information concerning all of your organization's alliances started between 1993 and 1996. It is not necessary that these alliances still exist in order to answer the questions.

1. How many alliances has your organization started between 1993 and 1996 ?

2. What are the objectives of these alliances? If an alliance has more than one objective multiple objectives should be indicated. (please estimate the number of alliances involved)

3. From which countries do your partners originate? (please estimate the number of alliances involved)

4. Are the partners in your alliances also your competitors?

B. Success of your alliances

5. Please rate the success of the alliances of your organization for each of the following success indicators. Did the alliances perform above or below expectations? (please circle the number)

6. Is the success of alliances with partners from particular geographic areas higher or lower than with partners from other areas? Please circle 'success-areas' or 'problemareas' below.

7. Is the success of alliances with a particular objective higher or lower than those with other objectives? Please circle the 'success-objectives' or 'problem-objectives' below.

8. How is the performance of alliances with your competitors? (if you do not have alliances with competitors please skip)

C. Knowledge and experience of alliances within your organization. These questions refer to the situation in your organization between 1993 and 1996.

9. On which level in the organization were alliance specialists (someone who is responsible for more than one alliance) located?

10. In which phase of an alliance is the alliance specialist involved?

11. Which were the most important criteria for selecting people directly responsible for alliances? (multiple answers possible, max. 2 answers)

12. Which criteria were used to evaluate the performance of an alliance? (multiple answers possible)

13. Which method was used to evaluate alliance performance?

14. How was the performance of your organization's alliances compared among each other?

15. By whom were alliance-involved managers trained or prepared for the alliances? (multiple answers possible)

16. How did this training occur?

\section{References}

1. KPMG Alliances, Alliances and networks: the next generation, Amsterdam (1996).

2. See for example J. R. Harbison and P. Pekar, Cross-Border Alliances in the Age of Collaboration, BoozAllen \& Hamilton (1997).

3. Based on an interview with an HP alliance manager and J. R. Harbison and P Pekar, Institutionalising Alliance Skills, BoozAllen \& Hamilton (1997).

4. See for example C. K. Prahalad and G. Hamel, The Core Competence of the Corporation, Harvard Business Review, August, 70-91(1990). 
5. B. N. Anand and T. Khanna, Do firms learn how to create value? The case of strategic alliances, Strategic Management Journal 21, 295-315 (2000).

6. P. Mariti and R. H. Smiley, Co-operative agreements and the organization of industry, Journal of Industrial Economics 31(4), 437-451(1983); G. Hamel, Y. Doz and C. K. Prahalad, Collaborate with your competitors and win, Harvard Business Review 67(1) 133-139 (1989); W. Shan, An emperical analysis of organizational strategies by entrepreneurial high technology firms, Strategic Management Journal 11(2), 129-139 (1990); G. Hamel, Competition for competence and inter-partner learning within international strategic alliances, Strategic Management Journal Summer Special Issue, 12, 83-103 (1991); W. Powell and P. Brantley, Competitive cooperation in biotechnology: learning through networks?, In N. Nohria and R. Eccles (eds.), Networks and Organizations: Structure, Form and Action, Harvard Business School Press, Boston, MA, 365-394 (1992); A. Mody, Learning through alliances, Journal of Economic Behavior and Organization 20, 151-170 (1993); T. Khanna, Winner-take-all alliances, Harvard Business School Working Paper, no. 96-033 (1996).

7. B. Wernerfelt, A resource based view of the firm, Strategic Management Journal 5(2), 171-180 (1984); J. Barney, Firm resources and sustained competitive advantage, Journal of Management 17(1), 99-120 (1991); D. J. Teece, G. Pisano and A. Shuen, Dynamic capabilities and strategic management, Strategic Management Journal 18(7): 509-533 (1997); R. R. Nelson and S. G. Winter, An Evolutionary Theory of Economic Change, Cambridge, MA: The Belknap Press (1982); B. Kogut and U. Zander, Knowledge of the firm, combinative capabilities and the replication of technology, Organization Science 3, 383-397 (1992); K. Conner and C. Prahalad, A resource-based theory of the firm: knowledge versus opportunism, Organization Science 7(5), 477-501 (1996); R. M. Grant, Toward a knowledge-based theory of the firm, Strategic Management Journal 17(winter special issue), 109-122 (1996).

8. H. W. Volberda and T. Elfring, Rethinking Strategy, Sage, London (2001).

9. R. M. Grant, Prospering in dynamically-competitive environments: organizational capability as knowledge integration, Organization Science 7(4), 375-387 (1996).

10. P. J. Lane and M. Lubatkin, Relative absorptive capacity and interorganizational learning, Strategic Management Journal 19, 461-477 (1998).

11. F. A. J. van den Bosch, H. W. Volberda and M. de Boer, Coevolution of firm absorptive capacity and knowledge environment: organizational form and combinative capabilities, Organization Science 10(5), 551-568 (1999).

12. P. Kale, J. H. Dyer and H. Sing, Alliance capability, stock market response, and long-term alliance success: the role of the alliance function, Strategic Management Journal 23(8), 747-767.

13. T. S. Robertson and H. Gatignon, Technology development mode: a transaction cost conceptualisation, Strategic Management Journal 19, 515-531 (1998).

14. W. W. Powell, K. W. Koput and L. Smith-Doerr, Interorganizational collaboration and the locus of innovation: networks of learning in biotechnology, Administrative Science Quarterly 41, 116-145 (1996).

15. B. N. Anand and T. Khanna, (see Reference 5) (2000).

16. M. J. Dollinger, P. A. Golden and T. Saxton, The effect of reputation on the decision to joint venture, Strategic Management Journal 18(2), 127-140 (1997); T. E. Stuart, Network propositions and propensities to collaborate: an investigation of strategic alliance formation in a high-technology industry, Administrative Science Quarterly 43, 668-698 (1998).

17. L. Hakansson, Managing cooperative research and development: partner selection and contract design, R\&D Management 23(4), 273-285 (1993).

18. R. E. Spekman, T. M. Forbes, L. A. Isabella and T. C. MacAvoy, Alliance management: a view from the past and a look to the future, Journal of Management Studies 35(6), 747-772 (1998).

19. G. Hamel, Y. Doz and C.K. Prahalad, Collaborate with your competitors and win, Harvard Business Review 67(1) 133-139 (1989); A. Inkpen, Learning, knowledge acquisition, and strategic alliances, European Management Journal 2, 223-229 (1998); D. Lei, J. W. Slocum and R. A. Pitts, Building cooperative advantage: managing strategic alliances to promote organizational learning, Journal of World Business 32(3), 203-223 (1997).

20. J. H. Dyer, P. Kale and H. Singh, How to make strategic alliances work, Sloan Management Review Summer, 37-43 (2001); P. Kale, J. H. Dyer and H. Sing Alliance Capability, stock market response, and long-term alliance success: the role of the alliance function, Strategic Management Journal 23(8), 747$767,2002$.

21. See for example: I. Nuance, A dynamic theory of organizational knowledge creation, Organization Science 5, 14-37 (1994). 
22. Spekman et al. (1998) (see Reference 18).

23. Anand and Khanna (2000) (see Reference 5).

24. A. P. De Man, H. Van der Zee and D. Geurts, Competing for Partners, Financial Times/Prentice-Hall, Amsterdam (2000).

25. A. W. Harzing, Response rates in international mail surveys: results of a 22 country study, International Business Review 6(6), 641-665 (1997); S. Dawson and D. Dickinson, Conducting international mail surveys: the effect of incentives on response rates within an industrial population, Journal of International Business Studies 19, 491-496 (1988); D. Jobber, H. Mirza and K. H. Wee, Incentives and response rates to cross-national business surveys: a logit model analysis, Journal of International Business Studies 22, 711-721 (1991).

26. J. M. Geringer and L. Hebert, Measuring performance of international joint ventures, Journal of International Business Studies 22, 249-263 (1991); G. G. Dess and R. B. Robinson Jr, Measuring organizational performance in the absence of objective measures: the case of the privately-held firm and conglomerate business unit, Strategic Management Journal 5, 265-273 (1984); E. Anderson, Two firms, one frontier: on assessing joint venture performance, Sloan Management Review Winter 1990, 19-30 (1990); B. Chakravarthy Measuring strategic performance, Strategic Management Journal 7(5), 437-458 (1986); J. P. Killing Strategies for Joint Venture Success, New York: Praeger (1983); J.-L. Schaan, Parent Control and Joint Venture Success: the Case of Mexico, Doctoral dissertation, University of Western Ontario (1983); J. Gill and R. Butler, Cycles of trust and distrust in joint-ventures, European Management Journal 14(1), 81-89 (1996).

\section{Biographies}

Johan Draulans was a trainee with KPMG Alliances (KPMG's competency centre in the field of alliances and networks) and is currently Assistant Professor of Strategic Management at the Department of Strategic Management \& Business Environment of the Rotterdam School of Management, Erasmus University and an economist at the Directorate Supervision Section Strategy at The Dutch Central Bank. (The views expressed in this article are those of the author and do not necessarily reflect the position of the Dutch Central Bank.) Department of Strategic Management \& Business Environment, Rotterdam School of Management, Erasmus University Rotterdam, P.O.box 1738, 3000 DR Rotterdam, The Netherlands. E-mail: J.Draulans@fbk.eur.nl Tel. 31-10 4081843

Ard-Pieter deMan is CEO of the Centre for Global Corporate Positioning, a firm dedicated to providing information about the alliance activity of companies. He also is associate professor of international business strategy at the University of Maastricht. E-mail: ard-pieter.de.man@cgcpmaps.com Tel. 31-6 51525811

Henk W. Volberda is Professor of Strategic Management and Business Policy and Chairman of the Department of Strategic Management \& Business Environment of the Rotterdam School of Management, Erasmus University. He is director of the Erasmus Strategic Renewal Centre, Board Member of the Rotterdam School of Management, and Adviser to Stroeve Stockbrokers. He has authored Building the Flexible Firm (Oxford University Press, 1998), Rethinking Strategy (Sage) and many journal articles. E-mail: H.Volberda@fbk.eur.nl Tel. 31-10 4082761 